\title{
Research Article \\ Effects of Clay and Moisture Content on Direct Shear Tests for Clay-Sand Mixtures
}

\author{
Muawia A. Dafalla \\ Civil Engineering Department, King Saud University, Riyadh 11421, Saudi Arabia \\ Correspondence should be addressed to Muawia A. Dafalla; mdafalla@ksu.edu.sa
}

Received 12 December 2012; Revised 20 December 2012; Accepted 21 December 2012

Academic Editor: Paolo Colombo

Copyright (c) 2013 Muawia A. Dafalla. This is an open access article distributed under the Creative Commons Attribution License, which permits unrestricted use, distribution, and reproduction in any medium, provided the original work is properly cited.

\begin{abstract}
The direct shear test using shear box is commonly recommended by practicing geotechnical engineers to obtain the cohesion and angle of internal friction for granular soils. The clay liners involve sand as a main constituent with added clay of variable proportions. This research aims at investigating the reliability of using the direct shear test for different clay contents and different moisture contents using an adequate shearing strain. These factors were found to affect the bilinear trends of shear force versus horizontal displacement profile as well as vertical displacement versus horizontal displacement curves. The cohesion of the mixture was found to increase consistently with the increase of clay content. Increase in moisture content was found to cause a drop in both cohesion and angle of internal friction. These changes are not independent of the density state of clay-sand mixtures. Standard compaction properties for a range of clay-sand mixtures were investigated. This work provides the general trends expected in direct shear tests for clay-sand mixtures of variable clay and moisture contents.
\end{abstract}

\section{Introduction and Background}

Artificial clay-sand mixtures were considered by design geotechnical and environmental engineers for use as hydraulic barriers. Adding clay to the sand helps in achieving low hydraulic conductivity. The term Bentonite Enhanced Sand (BES) was used by many researchers instead of clay sand mixtures, Studds et al. [1], Mollins et al. [2], and Stewart et al. [3]. As implied by the name the material is dominantly granular, and the amount of added clay is not large enough to classify the paste as anything other than sand. However there is a stage at which the paste starts behaving as pure clay when the sand grains are pushed apart, and clay dominates the engineering properties of the mix. The real boundary is not agreed upon as this is largely dependent on the activity and mineralogical composition of the clay. The ASTM standards classify the material as clay when the percentage of material passing sieve no. 200 is greater than $50 \%$, and the consistency tests indicate CL classification. In the British Soil Classification System, detailed in BS 5930 Site Investigation, little above $35 \%$ fines (material passing sieve no. 20063 microns) can lead to classify the material as clay.
A bentonite sand mixture of high clay content may no longer be considered as a BES.

This research work considers adding Al-Qatif expansive clays to sand at proportions of $5 \%$ to $15 \%$ as a first stage. Other percentages and combinations of Al-Qatif clay and commercial bentonite material were also considered as possible alternatives. However the study of the direct shear tests was concentrated on the local clay and sand mixtures. Compressibility and swelling tests were carried out on the mixtures to help understanding the trends and behaviour of the direct shear tests. Falling head permeability tests were conducted for 5 and 10\% clay-sand mixtures compacted to variable moisture contents at the maximum dry density.

The direct shear test is based on forcing the sample to fail along a predefined plane while being subjected to normal load. This gives a direct measure of the shear force capacity at specific conditions and enables determination of the angle of internal friction and cohesion. The shear stress in the shear box test is defined as the shear resistance developed within the sliding plane along a known section area of the sample.

The general trends of direct shear tests on sand and clays are shown on Figures 1 and 2. 


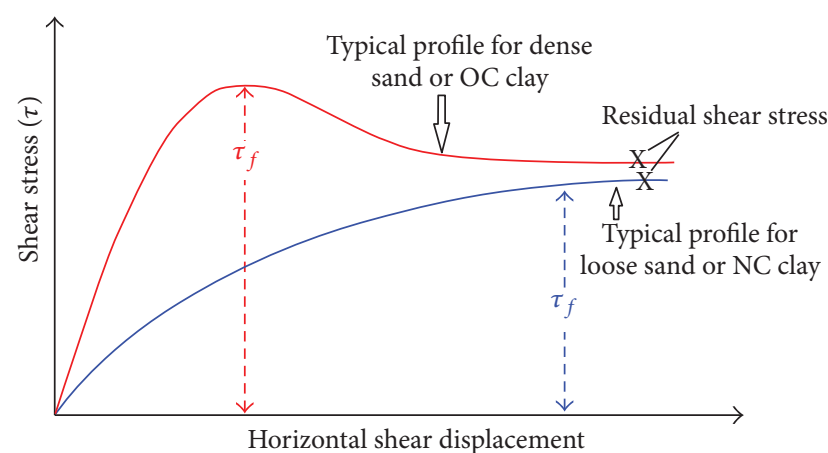

FIGURE 1: Typical shear stress versus horizontal shear displacement (OC stands for overconsolidated and NC stands for normally consolidated).

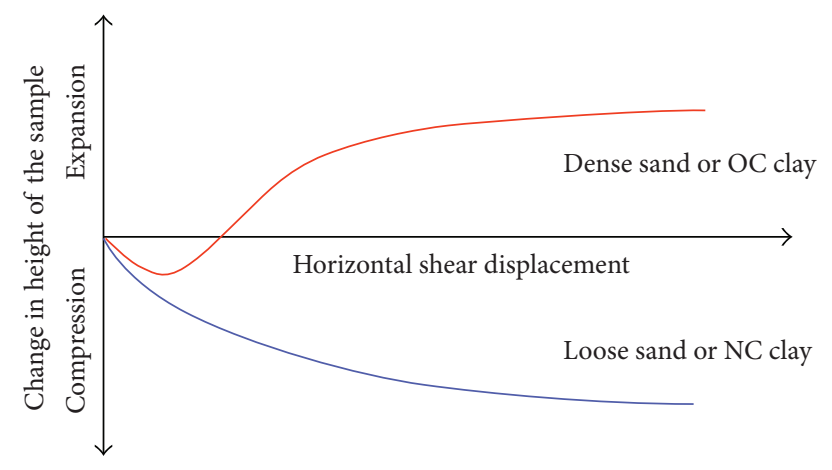

FIgURE 2: Typical vertical displacement versus horizontal shear displacement (OC stands for overconsolidated and NC stands for normally consolidated).

\section{Materials and Testing Methods}

2.1. Al-Qatif Clay. The clay soil studied in this paper was brought from Al-Qatif town in the Eastern Province of Saudi Arabia. The sand material used is typical fine-grained sand used in construction in the country. Characterization tests were carried out for Al-Qatif clay and the sand material. Classification tests included gradation, liquid limit, and plastic limit tests. The clay material was found to have high liquid limit and plastic limit and classified within $\mathrm{CH}$ group in accordance with the Unified Soil Classification System. Physical and chemical properties of Al Qatif clay are given in Tables 1 and 2, respectively.

The fine grained sand and several sand clay mixtures were investigated for compaction properties. Standard compaction tests were carried out in accordance with ASTM D 698 to establish the compaction characteristics of sand-clay mixtures.

2.1.1. Bentonite. The bentonite used in this study was HY OCMA obtained by a local supplier. The index properties of HY OCMA bentonite used in the present study are given in Table 3.

2.1.2. Sand. The sand used in this study was local sand obtained from within Riyadh city which is typical to that used

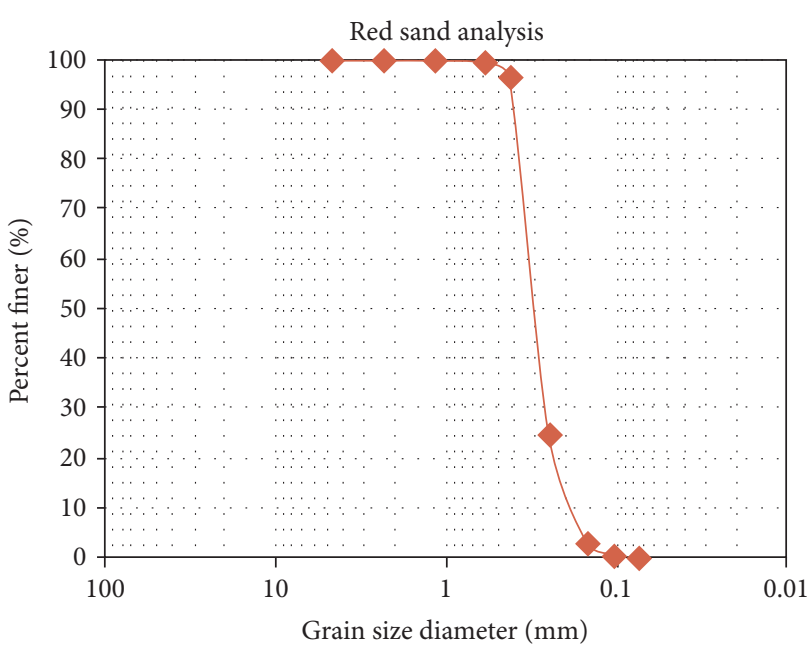

FIGURE 3: Grain sand distribution of sand.

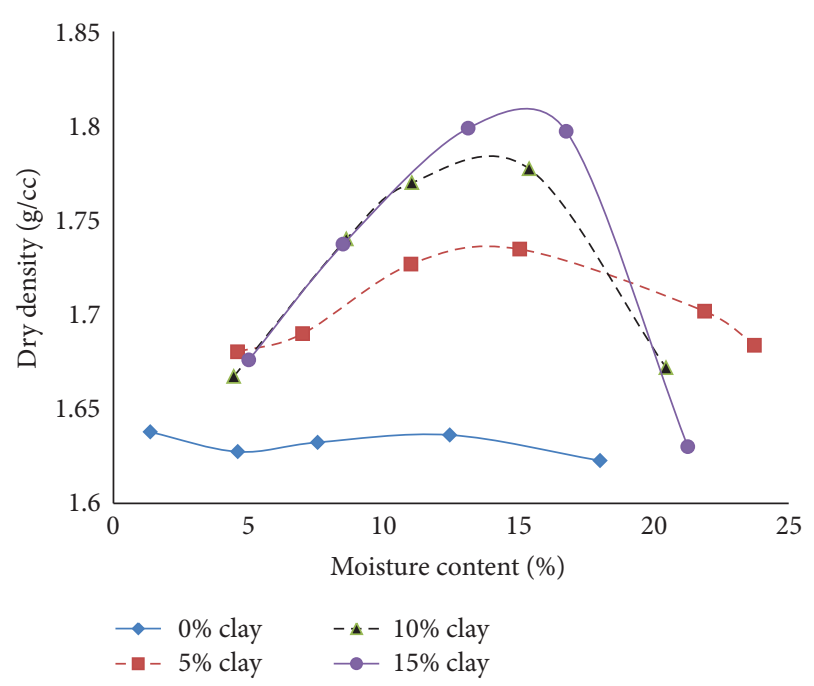

FIGURE 4: Compaction curves for sand-clay mixtures with different clay content.

TABLE 1: Physical properties of Al-Qatif clay.

\begin{tabular}{ll}
\hline Property & Range \\
\hline Material passing sieve no. 200 & $>90 \%$ \\
Liquid limit & $130-150$ \\
Plastic limit & $60-70$ \\
Plasticity index & $70-80$ \\
Maximum dry density & $1.150-1.200 \mathrm{gm} / \mathrm{cm}^{3}$ \\
Optimum moisture content & $32-40 \%$. \\
Swell per cent (ASTM D4546) & $16-18 \%$ \\
Swelling pressure (ASTM D4546) & $5.000-8.000 \mathrm{~kg} / \mathrm{cm}^{2}$ \\
\hline
\end{tabular}

After Dafalla et al. [4].

in construction throughout the Kingdom. This test is carried out to establish the percentage of different grain sizes present 
TABLE 2: Chemical composition of Al-Qatif clay.

\begin{tabular}{lccccccc}
\hline $\mathrm{K}^{+}(\%)$ & $\mathrm{K}_{2} \mathrm{O}(\%)$ & $\mathrm{Al}(\%)$ & $\mathrm{Al}_{2} \mathrm{O}_{3}(\%)$ & $\mathrm{Si}(\%)$ & $\mathrm{SiO}_{2}(\%)$ & $\mathrm{Ca}^{2+}(\%)$ & $\mathrm{CaO}^{2}(\%)$ \\
\hline 1.8 & 2.2 & 3.3 & 6.3 & 8.1 & 17.3 & 0.7 & 0.9 \\
\hline
\end{tabular}

After Dafalla et al. [4].

TABle 3: Properties of bentonite.

\begin{tabular}{lc}
\hline Property & Value \\
\hline Specific gravity, GS & 2.76 \\
Liquid limit, LL (\%) & 480 \\
Plastic limit, PL (\%) & 49.6 \\
Plasticity index, PI (\%) & 430 \\
\hline
\end{tabular}

Index property tests were carried out in the laboratory in accordance with BS 1377 Part 2: 1990.

in a soil. Procedure adopted for this test is ASTM D 422 Standard Test Method for Particle-Size Analysis of Soils.

The specific gravity of sand was 2.66 , and the grain size distribution of sand is presented in Figure 3. Values corresponding to uniformity and curvature coefficients are $\mathrm{Cu}=1.737$ and $\mathrm{Cc}=1.078$, respectively. $\mathrm{D}_{10}, \mathrm{D}_{50}$, and $\mathrm{D}_{90}$ were measured as $0.20 \mathrm{~mm}, 0.25 \mathrm{~mm}$, and $0.35 \mathrm{~mm}$ respectively.

The direct shear test was performed in accordance with ASTM standard D 3080 [5] for 15 clay-sand mixture samples grouped in sets of three so as to allow for variations in moisture content and clay content. The applied rate of strain was fixed at $0.12 \mathrm{~mm}$ per minute for all samples including the clay. The sample size was kept constant at $10 \mathrm{~cm}$ by $10 \mathrm{~cm}$. Normal stresses applied to each sample were $0.5,1.0$, and $1.5 \mathrm{gm} / \mathrm{cm}^{3}$. All samples were prepared at the maximum dry density as obtained in a standard compaction tests. The moisture range considered for the clay sand mixtures is $15 \%$, $17.5 \%$, and $20 \%$ whereas for the sand alone 7,10 , and $13 \%$ were selected. The pure Al-Qatif clay was tested for three moisture contents: $30 \%, 35 \%$, and $40 \%$, at a dry density of $1.200 \mathrm{gm} / \mathrm{cm}^{3}$. The moisture content values given here are all related to the initial state of the sample as the drained test does not allow measurements of moisture during testing.

\section{Test Results and Discussion}

The test results of dry density moisture content relationships are shown in Figure 4. It can be observed that adding clay contributes in increasing the dry density of the mixture and rendered the optimum moisture content increase and shift towards the right of the curve. The sand used here is poorly graded type which involves more voids than well-graded type material. Adding small amounts of clay may not be sufficient to fill up all the voids. The more clay added will contribute in higher unit weight. For specific compaction energy the soil water and air phases get rearranged to give a maximum unit weight at optimum moisture content.

3.1. Trends of Direct Shear Tests. The general trends for varying moisture are found typical for all proportions except

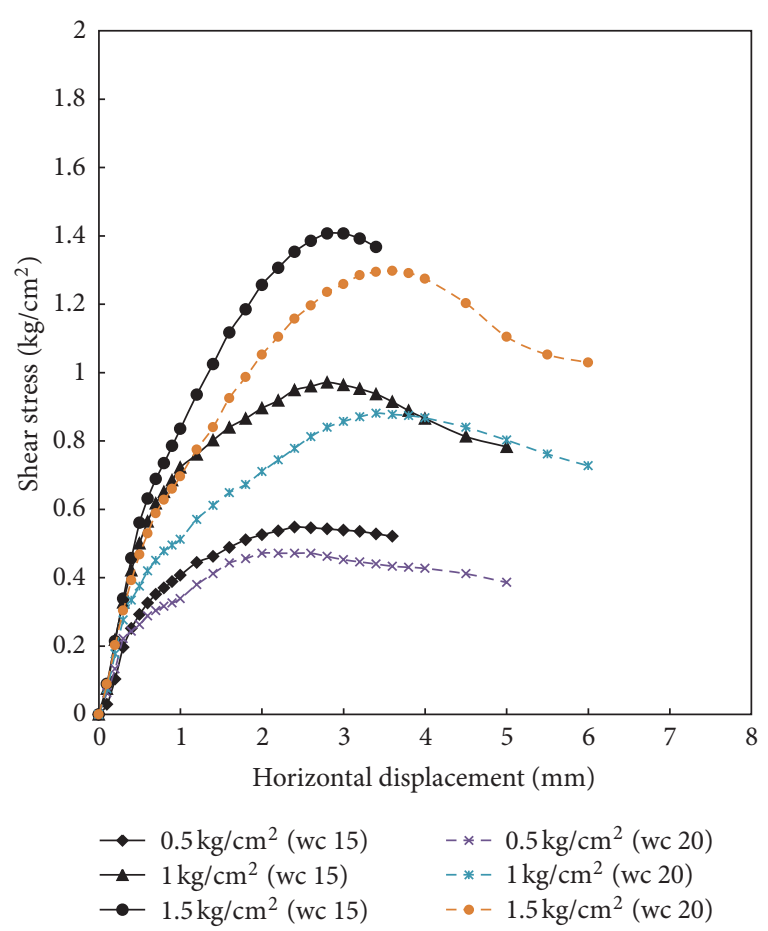

FIGURE 5: Shear stress versus horizontal displacement obtained from direct shear test.

for the magnitude of change. Three plots for the two extreme moistures tested for $5 \%$ clay sand mixtures are presented in Figures 5, 6, and 7 .

Shear stress versus horizontal displacement graph indicates a general bilinear plot for all normal stress values within the elastic zone. Plastic softening occurs close to the critical shear value, and the slope of shear stress versus horizontal displacement flattens and indicates a drop in the shear stress over a wide horizontal displacement compared to the elastic zone.

We can observe a drop in shear strength as a result of increasing the moisture content for all normal stresses. Defining dilation rate as the change of vertical displacement to horizontal displacement [6] we can see that the slopes are approximately similar but intercept the horizontal axis at variable points. Shifts in dilation slope intersection are observed due to increasing the moisture to $20 \%$. This shift is negative (less than $15 \%$ moisture intercept) for the normal stress of $0.5 \mathrm{~kg} / \mathrm{cm}^{2}$ and positive for normal stresses of 1.0 and $1.5 \mathrm{~kg} / \mathrm{cm}^{2}$.

The same comparison is applied to clay sand mixtures of variable clay content.

The general trends for varying clay content are found typical for all proportions except for magnitude of change. 
TABLE 4: Direct shear test results.

\begin{tabular}{lccccc}
\hline Sample no. & Clay $(\%)$ & Dry density $\left(\mathrm{g} / \mathrm{cm}^{3}\right)$ & Moisture content $(\%)$ & Cohesion $C, \mathrm{~kg} / \mathrm{cm}^{2}$ & Angle of friction $(\mathrm{degrees})$ \\
\hline DS-1 & 5 & 1.73 & 15 & 0.120 & 40.7 \\
DS-2 & 5 & 1.73 & 17.5 & 0.080 & 0.053 \\
DS-3 & 5 & 1.73 & 20 & 0.150 & 30.3 \\
\hline DS-4 & 10 & 1.77 & 15 & 0.120 & 39.6 \\
DS-5 & 10 & 1.77 & 17.5 & 0.090 & 39.0 \\
DS-6 & 10 & 1.77 & 20 & 0.260 & 38.6 \\
\hline DS-7 & 15 & 1.80 & 15 & 0.150 & 41.0 \\
DS-8 & 15 & 1.80 & 17.5 & 0.040 & 40.0 \\
DS-9 & 15 & 1.80 & 20 & 0.000 & 38.3 \\
\hline DS-10 & 0 & 1.63 & 7.0 & 0.010 & 43.0 \\
DS-11 & 0 & 1.63 & 10.0 & 1.090 & 41.0 \\
DS-12 & 0 & 1.63 & 13.0 & 0.900 & 38.6 \\
\hline DS-13 & 100 & 1.20 & 30.0 & 0.610 & 38.7 \\
DS-14 & 100 & 1.20 & 35.0 & 40.0 & 35.8 \\
DS-15 & 100 & 1.20 & & & 33.4 \\
\hline
\end{tabular}

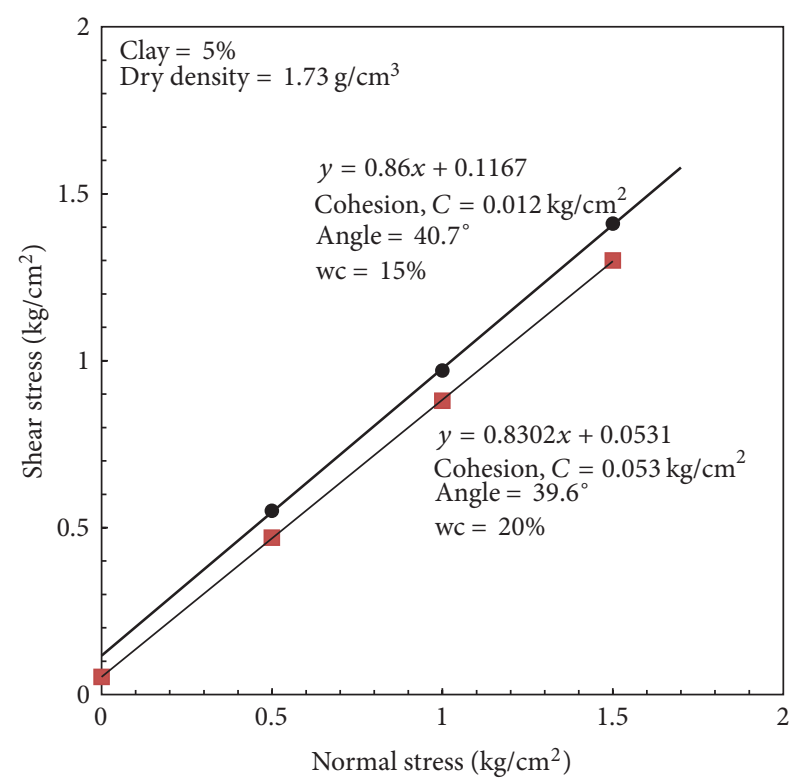

FIGURE 6: Shear strength envelope for clay-sand mixture.

Plots for the two extreme clay contents tested; $5 \%$ and $15 \%$ clay sand mixtures are presented in Figures 8, 9, and 10.

The general trend of shear stress versus horizontal displacement graph showed exactly the same bi-linear profile over the three normal stress values within the elastic zone. Three different shear moduli can be computed, at the initial stage of the test, before the critical shear, and beyond the critical shear value. The second value within the elastic zone is more appropriate for use in practical purposes.

We can observe an increase in shear strength as a result of increasing the clay content for all normal stresses. Dilation rates observed due to increasing the clay to $15 \%$ looks approximately similar, but the intercept with the horizontal displacement axis is negative (less than the intercept of $5 \%$

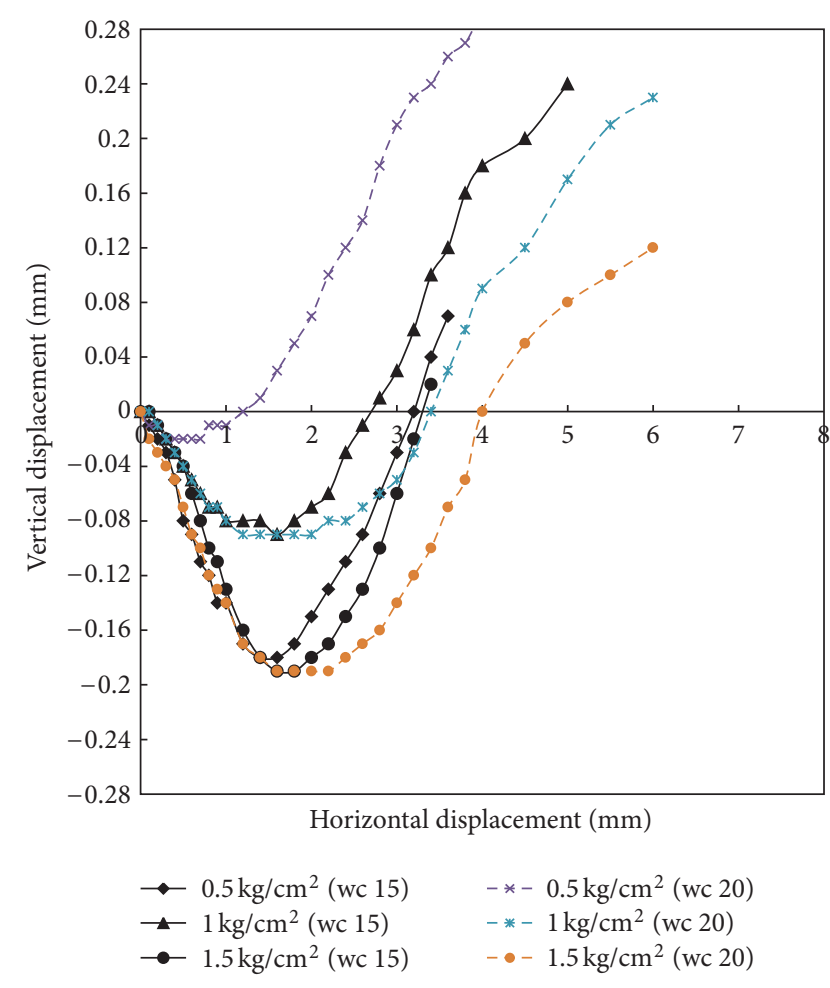

FIGURE 7: Vertical displacement versus horizontal displacement obtained from direct shear test.

clay) for the normal stress of $0.5 \mathrm{~kg} / \mathrm{cm}^{2}$ and positive for normal stresses of 1.0 and $1.5 \mathrm{~kg} / \mathrm{cm}^{2}$.

Summary of direct shear tests conducted on all samples is presented in Table 4.

3.2. Effect of Moisture Content. The influence of moisture content on both shear strength parameters is very significant. 


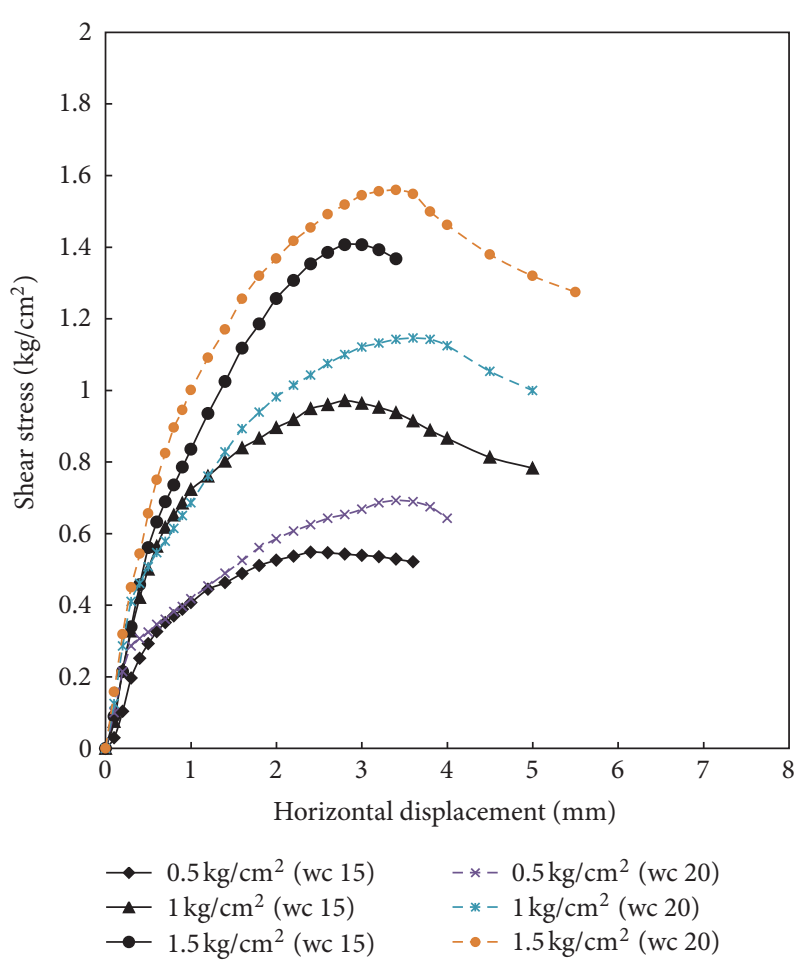

FIGURE 8: Shear stress versus horizontal displacement obtained from direct shear test.

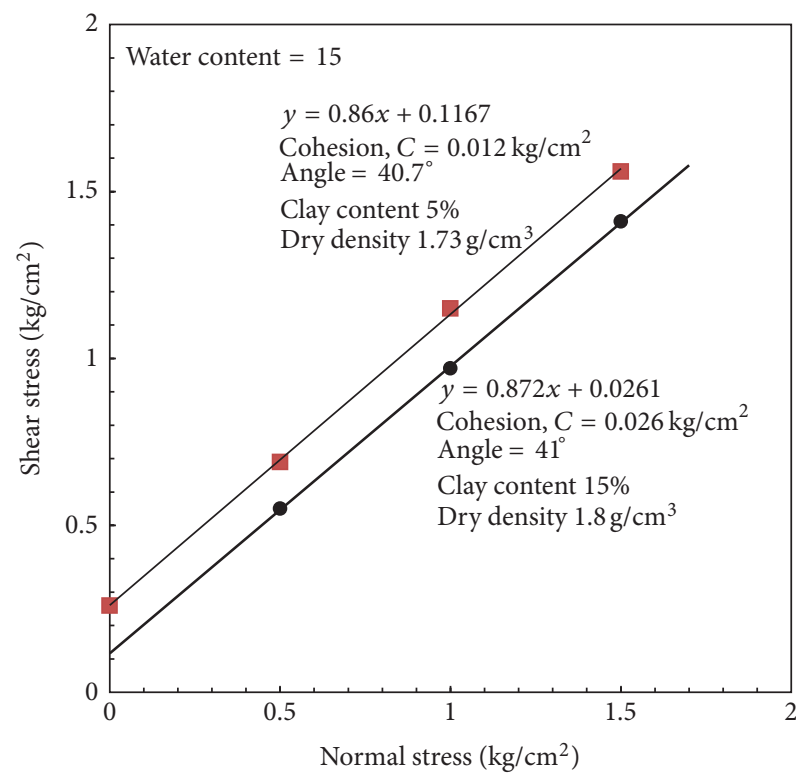

FIGURE 9: Shear strength envelope for clay-sand mixture.

As can be seen from the charts in Figure 11 the 15\% claysand mixture is showing steep drop (6\%) compared to $5 \%$ and $10 \%$ clay-sand mixtures where the drop is in the order of 2 to $3 \%$. The pure sand or clay is not plotted on the chart due to scale reasons. However the sand indicated zero cohesion at 7\% moisture content, and the angle of internal friction was measured at 43 degrees. Increasing water content

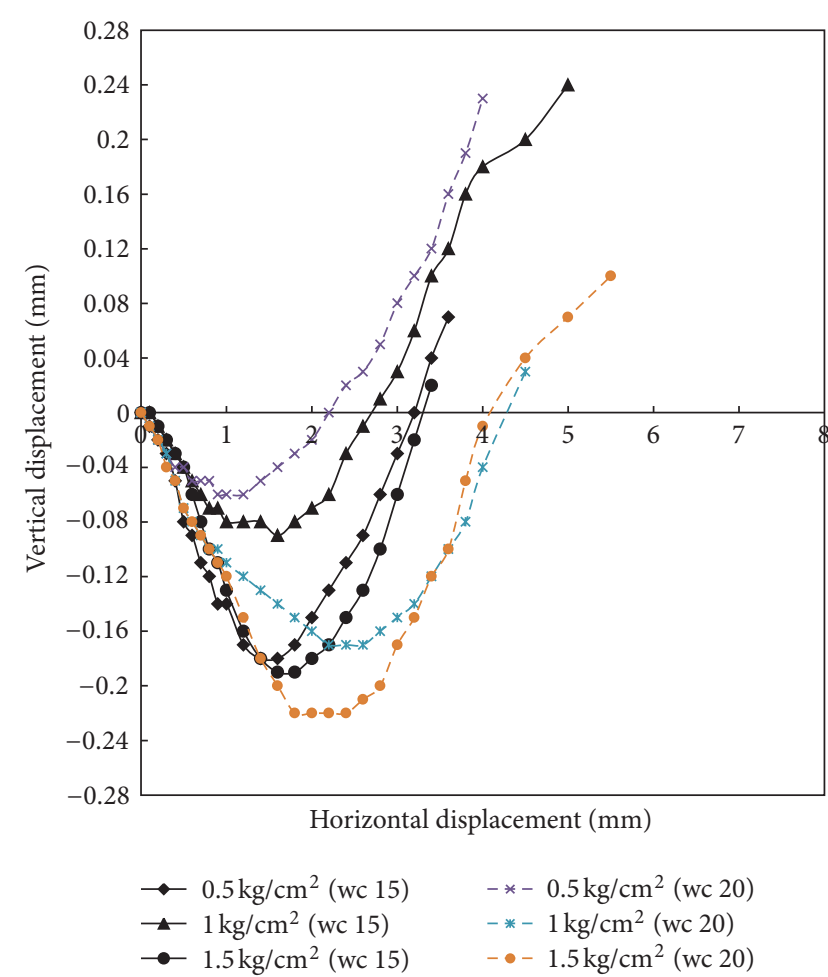

FIGURE 10: Vertical displacement versus horizontal displacement obtained from direct shear test.

of pure sand was found to cause drop of the angle of internal friction. Information on the pure clay behavior are given in the following section.

3.3. Effect of Clay Content. The presence of clay within the mix has its serious impact on the cohesion and the angle of internal friction. For moisture content slightly above the optimum moisture content the clay addition improves the cohesion of the mix. This improvement may not be attained if the moisture is far above the optimum moisture content. This limited data cannot give precise ranges but are sufficient to confirm the trend. Figure 12 presents the influence of clay content on the cohesion and friction angle. The angle of internal friction was shown to give a minimum value at $10 \%$ clay content for nonmoist mixtures, while it slides to less than 38 degrees for a clay-sand mixture of $20 \%$ moisture content. The influence of clay content on both shear strength parameters is very significant. As seen from the charts in Figure 12 , the $20 \%$ moist clay sand mixture is showing steep drop in both cohesion and angle of internal friction when the clay content is high. The pure clay is not plotted on the chart, but the drop of the angle of internal friction is almost $14 \%$ less when moisture is increased from $30 \%$ to $40 \%$ associated with a drop of cohesion from 1.13 to $0.61 \mathrm{~g} / \mathrm{cm}^{2}$, respectively.

3.4. Effect of Other Factors. There are many factors that have some influence on the shearing process. The effect of shearing rate is significant and depends on the testing arrangements with regard to drainage conditions and the type of soil 


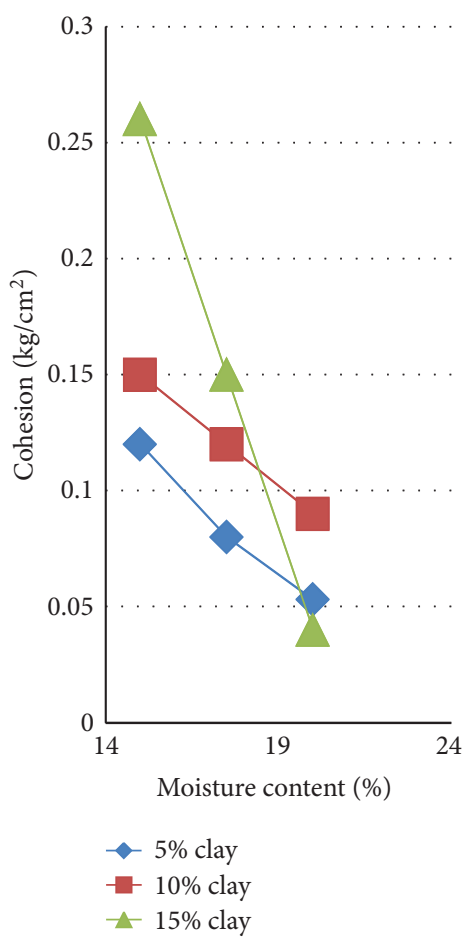

(a)

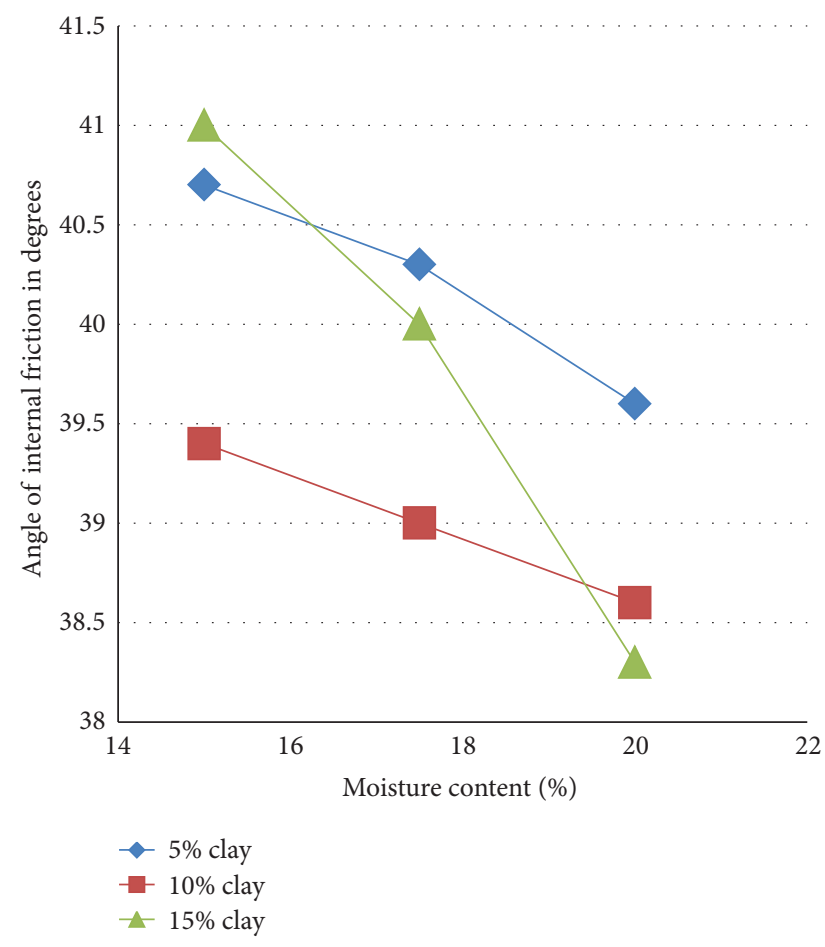

(b)

FIGURE 11: Influence of moisture on friction angle and cohesion.

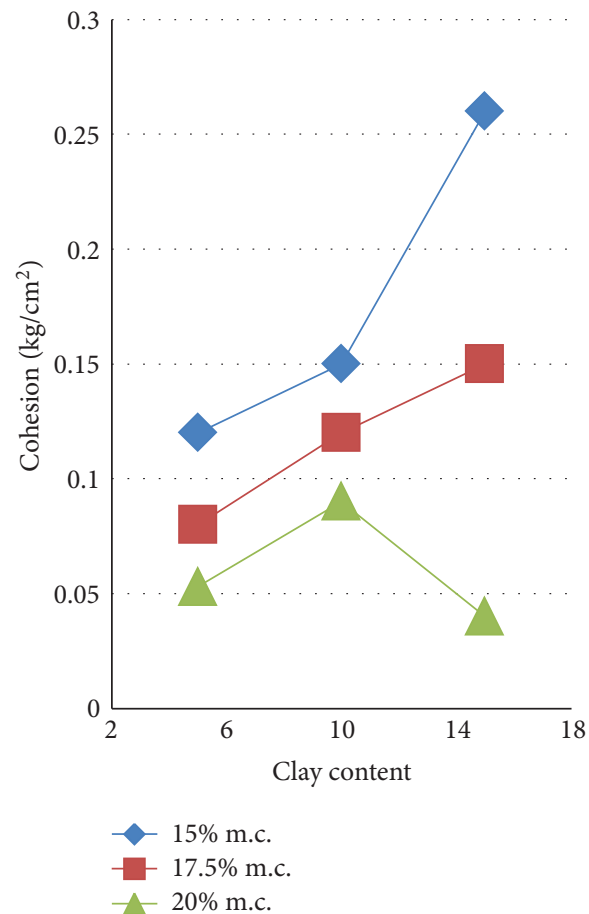

(a)

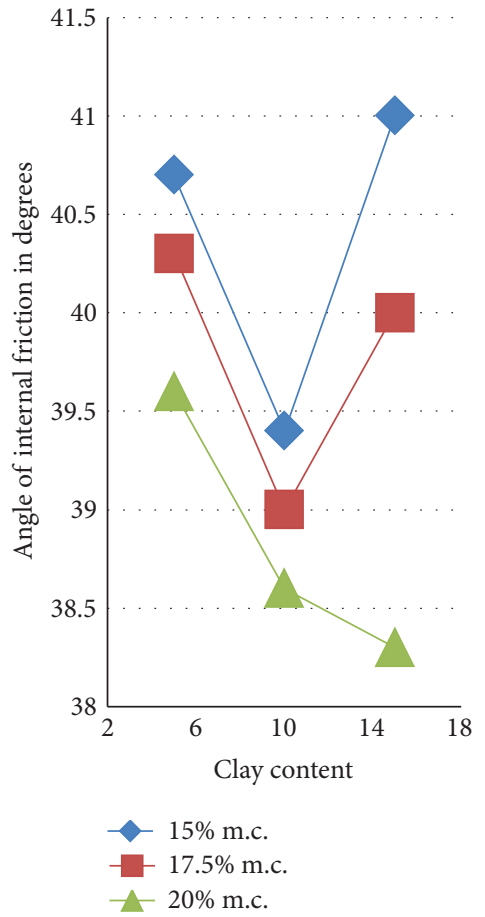

(b)

FIGURE 12: Influence of clay content on friction angle and cohesion. 
tested. In clays the rate of strain shall be very low to allow for dissipation of pore water pressure. Several days may be required to finish a single test. However drained strength obtained in a test using a rate of 1.2 to $1.3 \mathrm{~mm} / \mathrm{min}$ can give a better approximation for undrained specimen (Bowles, [7]). Ladd [8] claimed that undrained shear strength increases with the increase of rate of shear strain. It is worth mentioning that measured strength parameters need to be obtained in a manner simulating the site conditions. If the desired conditions are drained too fast, rate may not be appropriate. Bro et al. [9] stated that drainage conditions within clay test specimens are greatly affected by shear displacement rate. Boulanger and Idriss [10] stated that fast direct shear tests would underestimate undrained strength.

The mineralogy can have a major role in the shearing strength capacity of clays. The cementation between particles can either be due to a chemical bond or physicochemical bond. Swelling and shrinkage in expansive soils are of two extreme opposite effects on the shearing strength. The shear strength is generally low for fully expanded clay while dry shrinking clay is capable of developing higher cohesion and angle of internal friction.

The state of compaction or compaction energy applied to the sample will force the sand particles to closer contact. The measure of the dry density level in terms of maximum dry density as obtained in standard or modified proctor will give a good guide.

The sand shape whether rounded, subrounded, or angular will affect the shearing strength of a tested formation. Angular grains provide more interlock and increased shear resistance. The gradation and size of the sand affect the shear resistance. Well-graded materials provide more grain to grain area contact than poorly graded materials. Porosity and spaces available for clay within the sand is an important thing to look at when considering mixtures of clays and sands.

It is known that the denser the sample is the more shear resistance is expected. The unit weight or bulk density of clay sand mixtures is then crucial in determining its influences on the shearing resistance. In this study mixtures were compacted to its maximum dry density as per standard proctor compaction, and this is the state practicing engineers will consider when recommending a fill. Qualitatively we can say that all mixtures were brought to a very dense state. The particle size distribution (PSD) is a good measure of the soil grading. Well-graded soil samples are expected to achieve a shear strength higher than poorly graded material. Poorly graded material involve more voids and less particleto-particle contact. The role of little clay within the mix is unlikely significant if the sand particles are in full contact or interlocked at the density state described. Shear strength partitioning between clay and coarse grains is expected when the amount of clay is such that contact between grains is possible. The shear resistance of water within the pores is almost zero, but the water can enable particle-to-particle contact and help in compactness of the clay. Excessive water will reduce the overall shear strength. The outcome of this study is valid for the type of soil tested. Soils of different mineralogy may behave in a different way. It is suggested for future studies to investigate the soil water characteristics of the fine part of the mixture and compare the shear strength for different moisture levels. In general it may be possible to consider the water content of the mixture as being fully used by the clay.

The dilation of sand in direct shear test is density related and also dependent on the confinement conditions.

Although the direct shear is a rather quick test compared to consolidated drained triaxial test it has its own disadvantages. Uniformity and repeatability are relatively poor as area of sliding surface keep changing as the test progress. It is expected that the stress distribution of shear stresses along the failure plane surface is to be nonuniform.

\section{Summary and Conclusion}

The direct shear test can confidently be used for clay-sand liner materials provided that the material is not classified within CL groups in accordance with BS 5930 or ASTM D 2487 . When clayey material is $35 \%$ or more, the mixture is classified as clay in British standards. The ASTM considers the material as clay when $50 \%$ passing sieve no. 200 are classified within CL groups. The direct shear test is more appropriate for dominantly granular soil material. Testing clay sand mixture for as little as three different moisture contents and different clay contents can give a guide for strength properties of other mixes at variable moisture and clay contents.

This approach can help in choosing the appropriate mix or applying corrections to the right quantity of clay to be added to achieve certain shear strength.

Very moist clay-sand mixture showed steep drop in both cohesion and angle of internal friction when the clay content is high.

Increase in shear strength was reported for the increase of Al-Qatif clay content for all normal stresses tested $(0.5,1.0$, and $1.5 \mathrm{~g} / \mathrm{cc}$ ). Dilation rates or slope lines observed due to increasing the clay content or moisture content were found similar but intercepting the horizontal displacement axis at different locations.

Increase in moisture content of Al-Qatif clay caused the cohesion to drop for $5 \%$ and $10 \%$ of Al-Qatif clay sand mixtures at a nearly similar rate, but the $20 \%$ clay mixture showed a very steep drop. Similarly the angle of internal friction rate of drop increased for the $20 \%$ moisture content.

Increase in clay can help in the increase of cohesion for $5 \%$ and $10 \%$ of Al Qatif clay. There will be a limit for clay content beyond which the cohesion can drop due to high water content.

The angle of internal friction has shown to give a minimum value for $10 \%$ clay content for non-moist mixtures while it slides to less than 38 degrees for a clay-sand mixture of $20 \%$ moisture content.

\section{Acknowledgments}

This paper is a part of a research project supported through NPST program by King Saud University, Project No. ENV 
1183. The author also thanks the staff of Bugshan Research Chair in Expansive Soils for their help and support.

\section{References}

[1] P. G. Studds, D. I. Stewart, and T. W. Cousens, "The effects of salt solutions on the properties of bentonite-sand mixtures," Clay Minerals, vol. 33, no. 4, pp. 651-660, 1998.

[2] L. H. Mollins, D. I. Stewart, and T. W. Cousens, "Drained strength of bentonite-enhanced sand," Geotechnique, vol. 49, no. 4, pp. 523-528, 1999.

[3] D. I. Stewart, P. G. Studds, and T. W. Cousens, "The factors controlling the engineering properties of bentonite-enhanced sand," Applied Clay Science, vol. 23, no. 1-4, pp. 97-110, 2003.

[4] M. A. Dafalla, M. A. Al-Shamrani, and A. Obaid, "Reducing erosion along the surface of sloping clay-sand liners," in Proceedings of the ASCE Geo-Congress, San Diego, Calif, USA, March 2013.

[5] American Society for Testing and Materials, Designation: D, 3080/D, 3080M-11, Standard Test Method for Direct Shear Test of Soils under Consolidated Drained Conditions, vol. 4.08 of Annual Book of ASTM Standards, 2011.

[6] A. Hamidi, V. Yazdanjou, and N. Salimi, "Shear strength characteristics of sand-gravel mixtures," International Journal of Geotechnical Engineering, vol. 3, no. 1, pp. 29-38, 2009.

[7] J. Bowles, Foundation Analysis \& Design, McGraw-Hill, New York, NY, USA, 5th edition, 1995.

[8] C. C. Ladd, "Stability evaluation during staged construction," Journal of Geotechnical Engineering, vol. 117, no. 4, pp. 540-615, 1991.

[9] A. D. Bro, J. P. Stewart, and D. Pradel, Estimating Undrained Strength of Clays from Direct Shear Testing at Fast Displacement Rates, Proceedings of ASCE Geocongress, 2013.

[10] R. W. Boulanger and I. M. Idris, "Evaluation of cyclic softening in silts and clays," Journal of Geotechnical and Geoenvironmental Engineering, vol. 133, no. 6, pp. 641-652, 2007. 

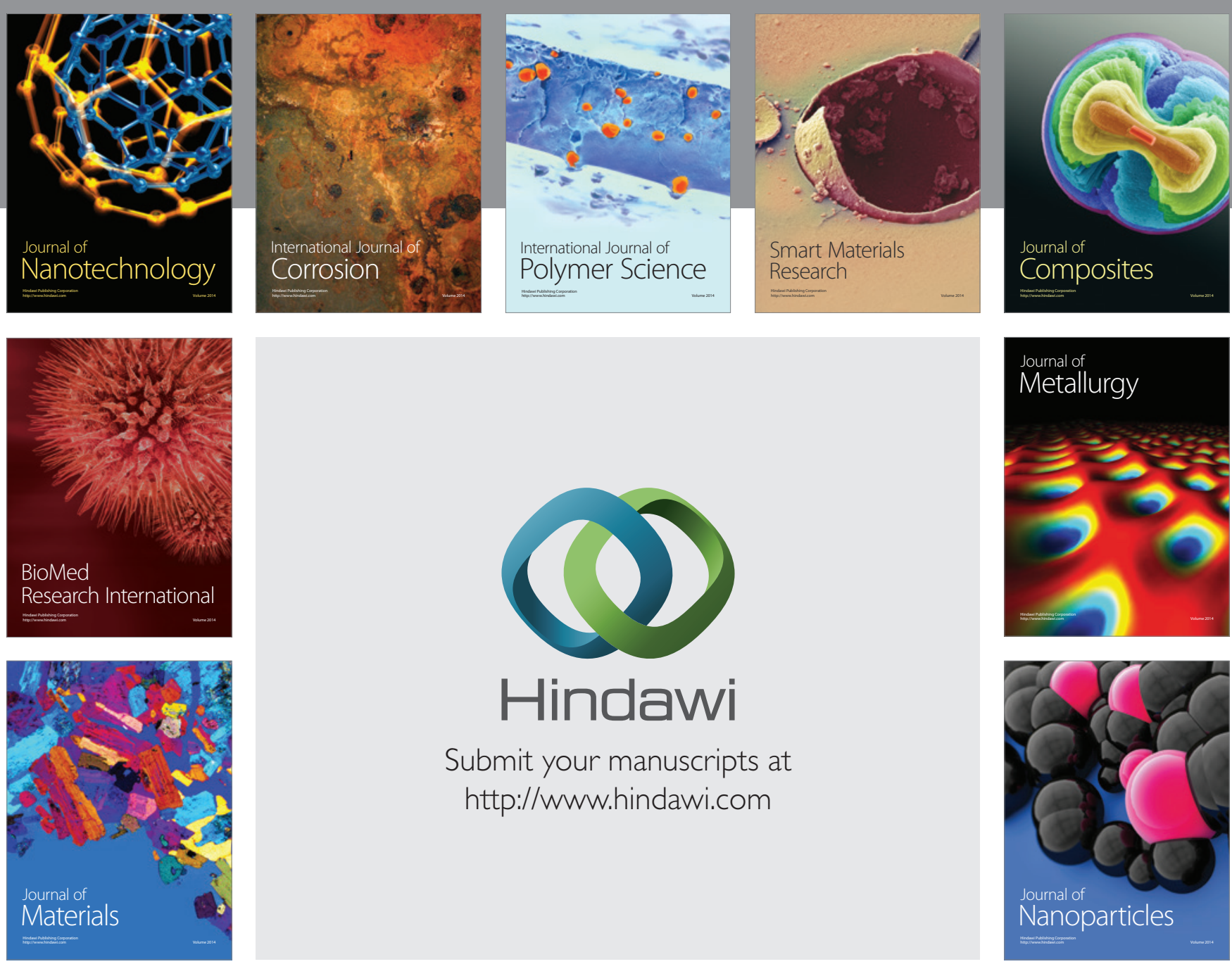

Submit your manuscripts at http://www.hindawi.com
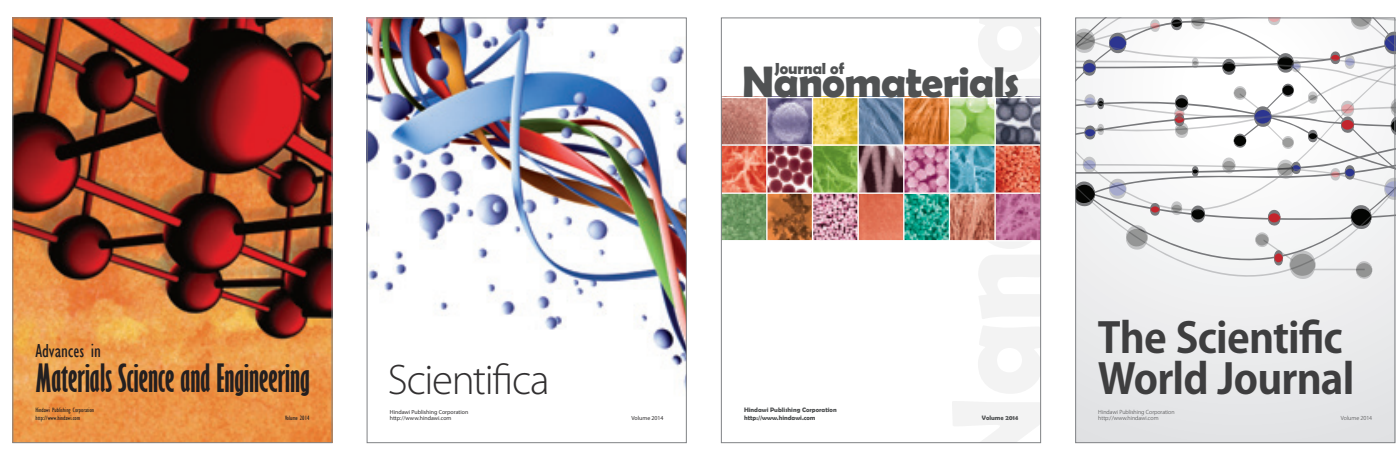

\section{The Scientific World Journal}
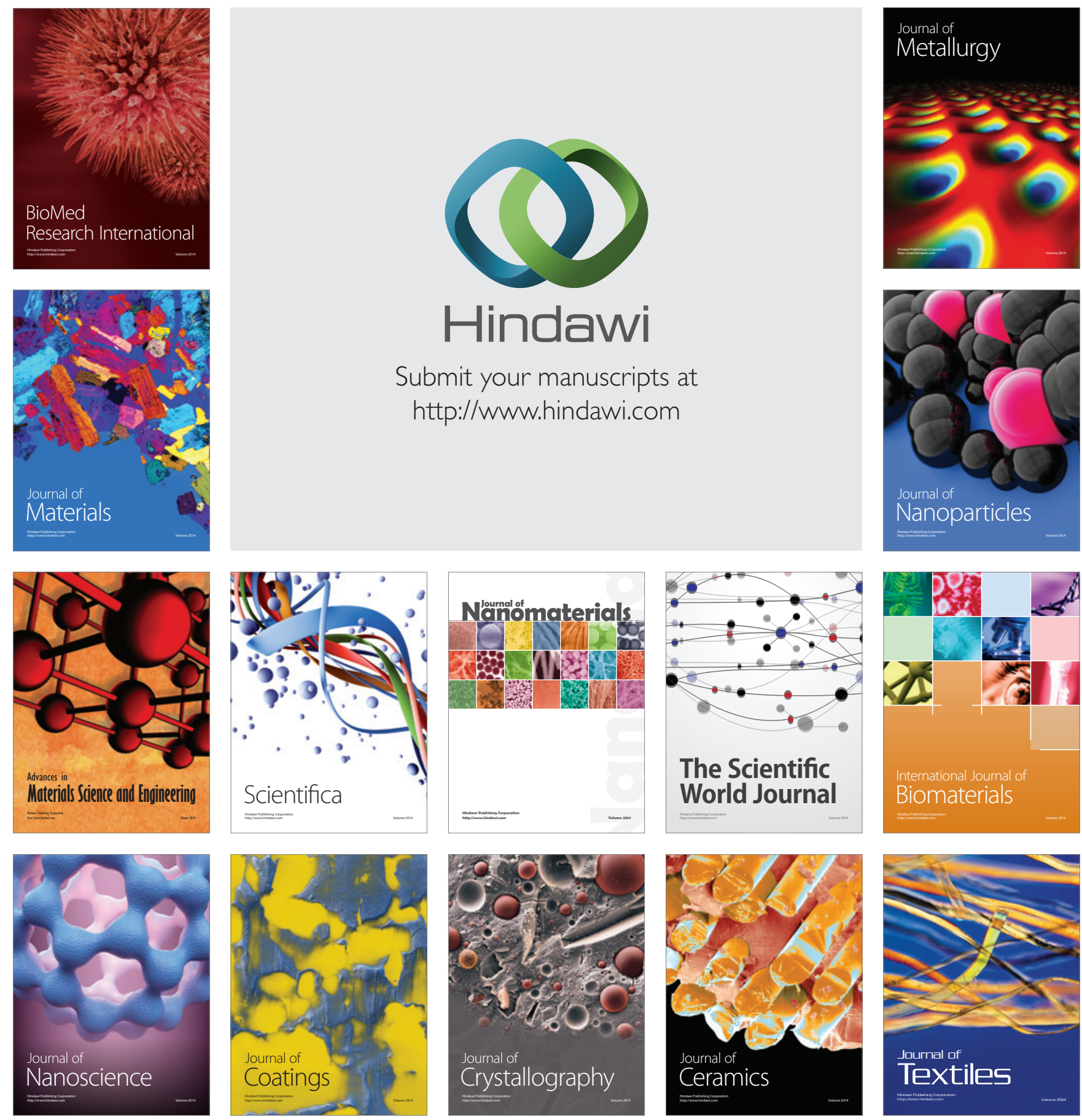